\title{
Assessment of the Impact of Natural Ventilation in the Renovated Katsina General Hospital, Katsina State, Nigeria.
}

\author{
*Fahad Abdulhamid", Rukayyatu Bashiru Tukur² \\ ${ }^{1}$ Department of Architecture, \\ Modibbo Adama University of Technology, \\ Yola \\ ${ }^{2}$ Department of Architecture, \\ Ahmadu Bello University, \\ Zaria \\ Email abdulhamidfahad@gmail.com
}

\begin{abstract}
The increasing cases of accidents, ailments, epidemics, pandemics (such as the most recent novel Corona virus) and growing population causes overcrowding and air stagnation. Low air velocity, dampness and high thermal discomfort in the interior of the hospitals causing series of deteriorations. These problems compelled the Katsina State Government to embark on general renovation and expansion of General Hospital Katsina adding more facilities to support the growing health needs of its citizens. The study aims to assess the impact of the renovation of the General Hospital Katsina which commenced late 2016 and completed in 2018 on natural ventilation considering the climate of the region. This study takes qualitative approach using physical measurement of temperature and air velocity before and after the successful renovation exercise. Data were collected from the study area. Comparison of indoor air velocity and air temperature as indicators of natural ventilation was done and air velocity increases to $0.06 \mathrm{~m} / \mathrm{s}$ while temperature dropped with $1^{\circ} \mathrm{C}$ which enhance thermal comfort. It is highly recommended that professionals should look into natural ventilation during design of hospitals.
\end{abstract}

Keywords: air temperature, air velocity, natural ventilation, Katsina General Hospital

\section{INTRODUCTION}

When we talk about the building interior, the comfort of the occupant is of great importance. This interior comfort of building occupants is achieved by a number of factors which include air circulation, humidity, and ambient temperature among others. The major source of that comfort is through ventilation which is divided into natural and mechanical (artificial) ventilation. Natural ventilation, as the name implies, is a system using natural forces to supply fresh air for comfort and heat dissipation. As an alternative to mechanical (fan-forced) ventilation, this approach relies on the natural forces of wind and buoyancy to deliver fresh air to indoor spaces (Batia, 2017). 
The function of ventilation can be categorized into two, which are for health and thermal comfort whereas the function for structural cooling included as part of a function of thermal comfort (Abdullahi, 2015). Health requirement is achieved through the exchange of internal air and fresh outdoor air with the unpleasant odour removed. For thermal comfort, air movement cools the body and removes excessive heat (Health and safety Executives, 2014). Ventilation is necessary in buildings to remove 'stale' air and replace it with 'fresh' air thereby helping to moderate internal temperatures, helping to moderate internal humidity, replenishing oxygen, reducing the accumulation of moisture, odours, bacteria, dust, carbon dioxide, smoke and other contaminants that can build up during occupied periods and creating air movement which improves the comfort of occupants.

The increasing cases of accidents, ailments, epidemics and growing population causes the overcrowding of the available hospital wards, departments and the whole hospital in general, which causes air stagnation as a result of low air velocity, dampness and high thermal discomfort in the interior of the hospital ward. These institutional buildings are often left without proper maintenance and record keeping for future use which causes the buildings to be in serious deterioration state. These problems compelled the Katsina State Government to embark on general renovation of the Katsina general hospital.

The study aims to assess the impact of the renovation of the general hospital Katsina which commenced in late 2016 and completed in 2018 on natural ventilation in view of the climate the region which is hot dry climate region in Nigeria (Tolupe and Parastoo, 2020). Katsina is located in hot dry climate which is characterized by excessive solar radiation; high daily temperature for a greater part of the year which results in very poor indoor thermal comfort hospital designs in the region not climate conscious.

Though it is difficult to satisfy everyone in a space due to physiological and psychological variation from person to person, thermal comfort is still one of the most significant factors affecting environmental satisfaction (Nazanin, Jones, \& Knight, 2008). The excessive heat generated from the sun's radiation in the tropics is the major cause of thermal discomfort. Natural ventilation is clearly a valuable tool for sustainable development as it relies on air movement, and can save significant amount of fossil fuel based energy by reducing the need for mechanical ventilation and air conditioning (Tukur, 2013). Reducing electrical energy used for cooling contributes to reduction of greenhouse gas emissions from electrical generating plant providing the energy (Health and Safety Executives, 2014). Natural ventilation relies on moving air in buildings under natural forces caused by outside wind pressure and the buoyancy effect of difference in temperature (Abdulhamid, 2018).

Air temperature is the most important environmental factor, measured by the dry bulb temperature (DBT). Air temperature is a measure of the heat or air temperature surrounding a body, and it is usually measured in degree Celsius $\left({ }^{\circ} \mathrm{C}\right)$ or degree Fahrenheit $\left({ }^{\circ} \mathrm{F}\right)$ (Health and Safety Executives, 2014). Most thermometers only measure ambient air heat, however, radiant heat loss or gain is also important. Radiant heat may not be reflected in the air temperature, but is the impact of cold or hot objects in the area. Generally, whenever the air temperature exceeds the temperature of the skin and the respired gases, it is difficult to maintain thermal comfort, (Abdulhamid, 2018).

Hospitals in Nigeria are classified according to Public Health Nigeria (2020), into primary healthcare (clinics, dispensary, district hospitals), secondary healthcare (usually general hospitals), and tertiary healthcare (federal medical centres, specialized hospitals and 
teaching hospitals). Hospitals are also classified by their ownership (not-for-profit, proprietary, or Government owned). Hospitals may be classified in three principal ways e.g. ownership, length of stay of patient, and types of services provided. District hospital are the first referral level that is responsible for a district of a defined geographical area containing a defined population and governed by a politico administrative Organization such as a district health management team. General hospital is set up to deal with many kinds of diseases and injury, and typically has an emergency department to deal with immediate and urgent threats to health. A general hospital typically is the major health care facility in its region, with large numbers of beds for intensive care and long-term care and specialized facilities for surgery, plastic surgery, childbirth, bioassay laboratories, and so forth. Specialized hospitals include trauma centres, rehabilitation hospitals, children's hospitals, maternity hospitals, seniors' (geriatric) hospitals, and hospitals for dealing with specific medical needs such as psychiatric problems, certain disease categories, and so on. While Teaching hospitals combines assistance to patients with teaching to medical students and nurses and often is linked to a medical school or nursing school. Some of these are associated with universities. The whole hospital system is to be tailored to respond to the health needs of the patients. Figure 1 shows a typical working system in a hospital with the diagnostic / treatment unit getting necessary support from the admin, in-patient, services and out-patient units.

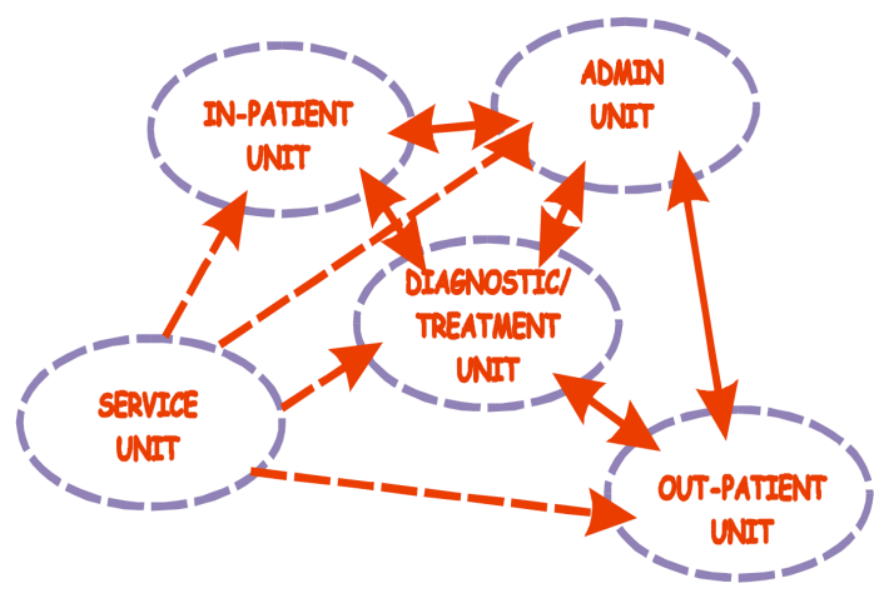

Figure 1. Hospital departments, (Source: www.wbgd.org/design_hospitals)

Administrative unit coordinates and regulates the running and management of the affairs of the hospital system. In-patient unit is concerned with patients that may require close monitoring and may need to stay overnight. Out-patient unit describes medical care or treatment that does not require an overnight stay in a hospital or medical facility. This is the first point of contact with the hospital. Diagnostic/treatment unit is concerned with the diagnosis of the different aliments and also treatment. The diagnosis may be in form of scanning in different forms ranging from X-rays, CT scans, MRI, etc.

The starting point in ventilation design is to determine how much ventilation air is required, and for what purposes. In North America, the most widely accepted standard for designing ventilation systems to achieve acceptable indoor air quality in buildings is the American Society of Heating, Refrigerating and Air-Conditioning Engineers (ASHRAE) Standard 622007, Ventilation for Acceptable Indoor Air Quality. For indoor air quality, the requirement for ventilation is based on the number of occupants and is $15 \mathrm{cfm}$ per person. This design capability is needed at all times in winter and summer. The ventilation principles used in the building to exploit the natural driving forces are single sided ventilation relies on airflow through openings on only one side of an enclosed space. Cross ventilation relies on airflow 
between ventilation openings on opposite sides of a space. Simply, the air enters from one opening (in the windward wall) and travels across the space to leave from another opening in the opposite side (in the leeward wall). Stack ventilation is driven through the building by thermal buoyancy.

\section{METHODOLOGY}

\section{Study Area}

The general hospital Katsina is located at the heart of Katsina city right behind the emir's palace. The hospital comprises of the units and departments expected of a general hospital. These are, general outpatient department, laboratory, dental clinic, eye clinic, ENT unit, admin, maternity, pharmacy, radiology department, paediatric department, inpatients' facilities, theatre, mortuary, workshops, kitchen/laundry, Accident and Emergency, medical record and few others. Architectural spatial design requirements consist of six basic units namely; the general outpatient department (GOPD), paediatric department, theatres, diagnostic imaging, administrative block and the laboratories. The other building units are; maternity, accident and emergency, ward and services.

Male ward three (3) was selected for the study as the data gotten from it during the renovation will be compared with the data after renovation. This is because during the first study by Abdulhamid and Tukur in 2019, the ward was the only one not touched by the renovation. As such gives the perfect opportunity for a complete report and documentation.
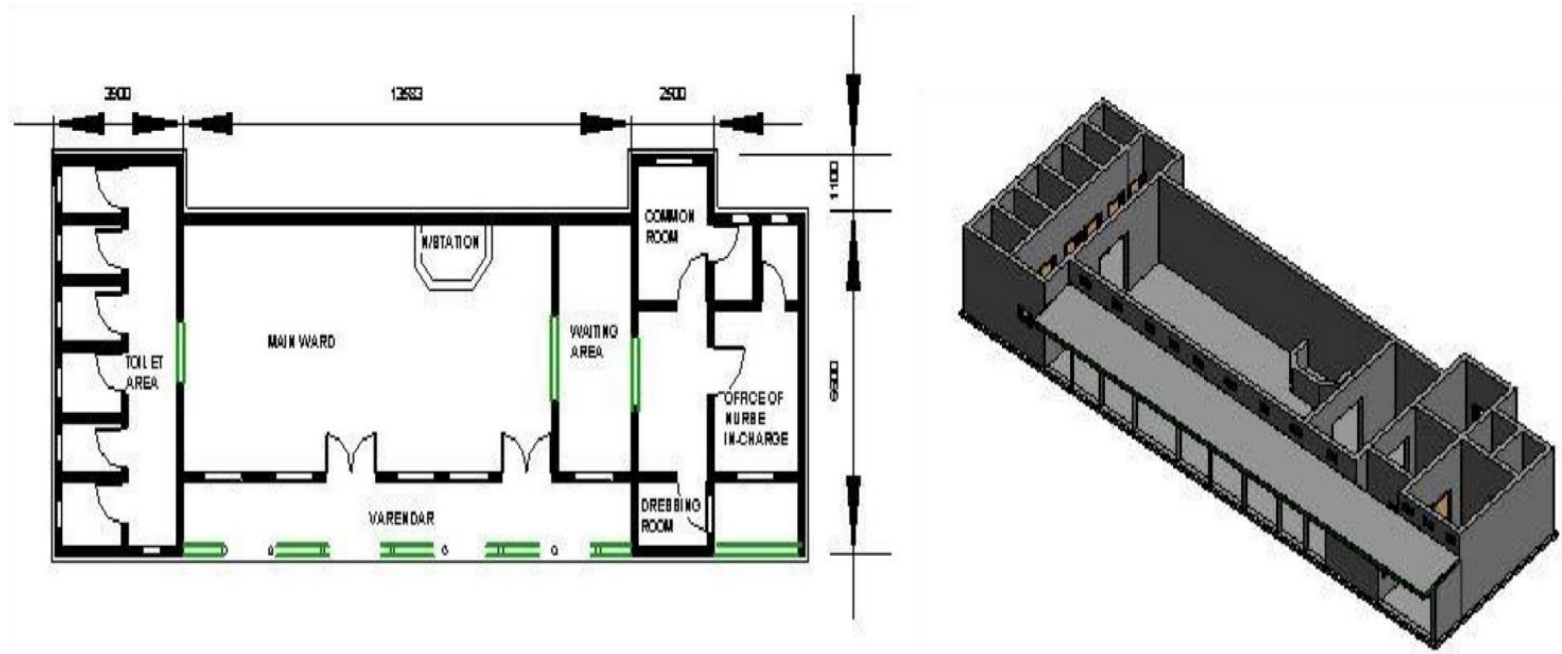

Figure 2: model of ward three (3) Source: Abdulhamid and Tukur, 2019.

\section{Data collection}

This study takes the quantitative approach which physical measurement using an instrument is called an Anemometer. Data for the analysis was obtained as recorded in a study "Exploring Solar Chimneys To Enhance Natural Ventilation Towards Aiding Thermal Comfort In The Design Of A Proposed General Hospital, Katsina" (Abdulhamid, 2018) before the commencement of the general renovation and the physical measurement after the completion of the renovation. A comparison is made of the indoor air velocity and air temperature before and after the renovation exercise as indicators of natural ventilation in a chosen ward 
The dependent variables are the predicted indoor air temperature, indoor air speed and thermal comfort. Thermal comfort is measured in terms of indoor dry bulb air temperature and operative temperature, both measured in degree Celsius $\left({ }^{\circ} \mathrm{C}\right)$ and air speed is measured in metre per second $(\mathrm{m} / \mathrm{s})$. Dry bulb temperature is the most common index for the specification of comfort (Nicol, Hunphreys, \& Roaf, 2012).

The measured data was recorded at three different points and the mean value recorded and done for some selected days of the year. The reason for the selection was on the basis of the days being the hottest days and months of the year. This gives adequate room for proper evaluation in terms of indoor air velocity and temperature.

\section{RESULTS}

The context of the entire result presented in this paper gives the outcome of the data collection exercise conducted for both 2015 and 2019. The selected days and months were all captured with averages obtained for both indoor air temperature and indoor air velocity which are enablers of thermal comfort. The influence of the elements of natural is seen on the averages of the highest and the lowest value obtained before and after the renovation exercise. At the end of the data presentation, a value is obtained which shows the degree of comfort received by the building occupants after the renovation exercise.

The reading of both indoor air temperature and velocity were taken in order to find the performance of natural ventilation elements on the hospital ward on selected days and months of the year 2015 and 2019. These days 5 April, 21 May and 15 June 2015 are found to be the hottest days and April, May and June the hottest months respectively.

For each day, the solar times selected ranges from $6 \mathrm{am}$ to $6 \mathrm{pm}$ corresponding to $6: 00$ to 18:00 hours GMT. The temperature recorded for the respective days are presented in the figure 3.

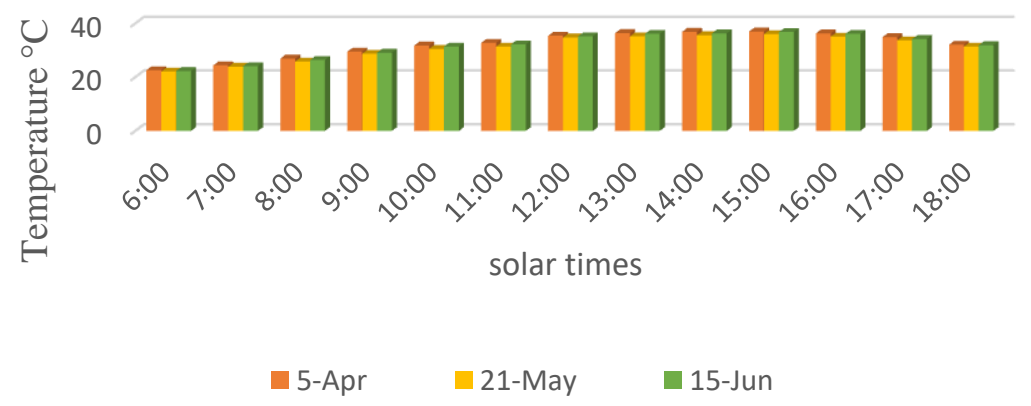

Figure 3 the indoor average air temperature at different solar times on 5 April, 21 May and 15 June 2015

The recorded result shown in figure 3 shows the lowest and the highest values of indoor temperatures recorded are $22.6^{\circ} \mathrm{C}$ and $37.0^{\circ} \mathrm{C}, 22.1^{\circ} \mathrm{C}$ and $36.0^{\circ} \mathrm{C}, 22.3^{\circ} \mathrm{C}$ and $36.8^{\circ} \mathrm{C}$ while their averages are $29.1^{\circ} \mathrm{C}, 29.05^{\circ} \mathrm{C}$ and $29.55^{\circ} \mathrm{C}$ for April $5^{\text {th }}, 21^{\text {st }}$ May and $15^{\text {th }}$ June respectively.

Figure 4 shows the recorded temperature of the hospital ward taken at the respective dates and times in the year 2019. 


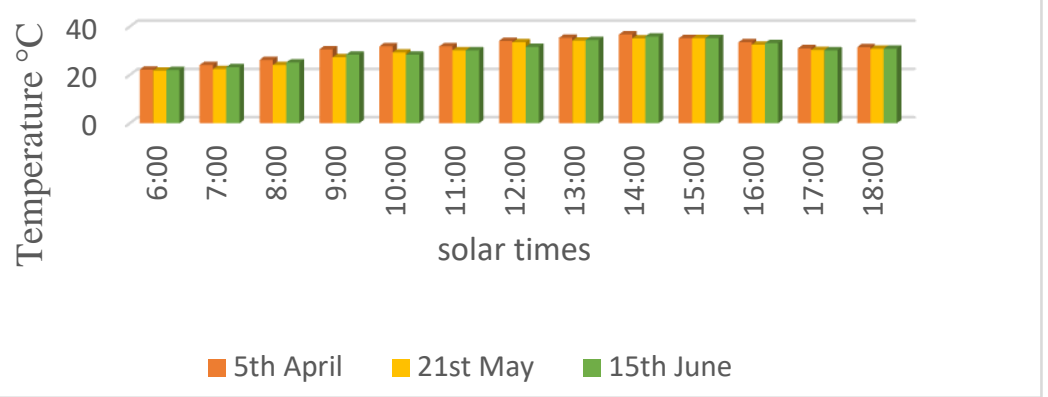

Figure 4 showing the hourly temperature of $5^{\text {th }}$ April, 21 ${ }^{\text {st }}$ May and $15^{\text {th }}$ June, 2019

The computation from figure 4 shows that the lowest and the highest values of indoor temperatures recorded are $22.2^{\circ} \mathrm{C}$ and $36.7^{\circ} \mathrm{C}, 21.8^{\circ} \mathrm{C}$ and $35.1^{\circ} \mathrm{C}, 22.0^{\circ} \mathrm{C}$ and $35.9^{\circ} \mathrm{C}$ while their averages are $29.45^{\circ} \mathrm{C}, 28.45^{\circ} \mathrm{C}$ and $28.95^{\circ} \mathrm{C}$ for April $5^{\text {th }}, 21^{\text {st }}$ May and $15^{\text {th }}$ June respectively.

The indoor air velocity was recorded also to check the effect of natural ventilation elements incorporated during the renovation exercise. Figure 5 shows the indoor air velocity recorded in the 2015 before the commencement of the renovation exercise.

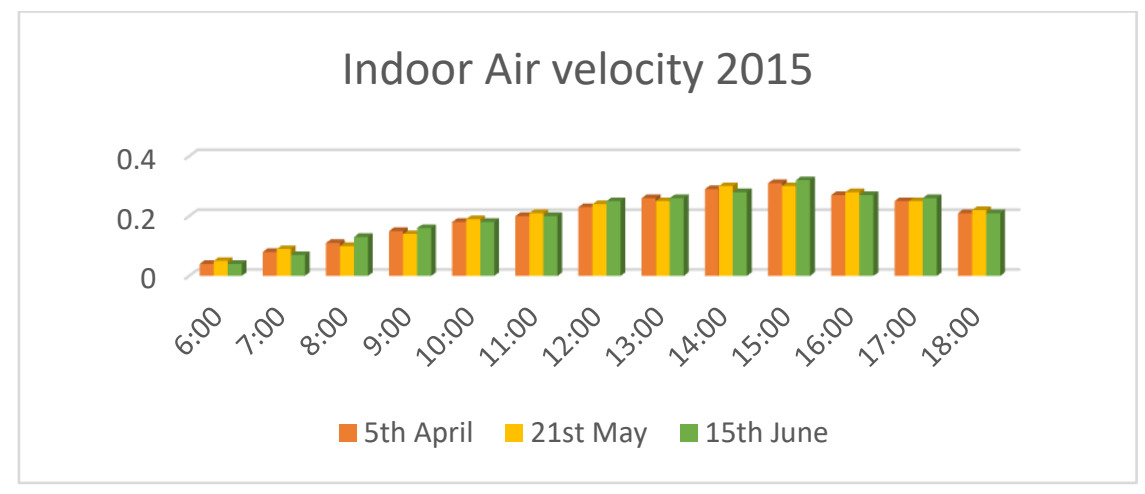

Figure 5 showing indoor air velocity for $5^{\text {th }}$ April, 21 ${ }^{\text {st }}$ May and $15^{\text {th }}$ June 2015

From figure 5, the lowest and the highest values of indoor air velocities recorded are 0.04 $\mathrm{m} / \mathrm{s}$ and $0.31 \mathrm{~m} / \mathrm{s}, 0.05 \mathrm{~m} / \mathrm{s}$ and $0.30 \mathrm{~m} / \mathrm{s}, 0.04 \mathrm{~m} / \mathrm{s}$ and $0.32 \mathrm{~m} / \mathrm{s}$ while their mean values are $0.175 \mathrm{~m} / \mathrm{s}, 0.175 \mathrm{~m} / \mathrm{s}$ and $0.18 \mathrm{~m} / \mathrm{s}$ for April $5^{\text {th }}, 21^{\text {st }}$ May and 15th June respectively.

The indoor air velocity of the hospital ward was recorded again in 2019 for corresponding months, dates and times with readings from figure 6. This is done to ascertain the improvement in the air flow of the interior of the hospital ward after the renovation exercise.

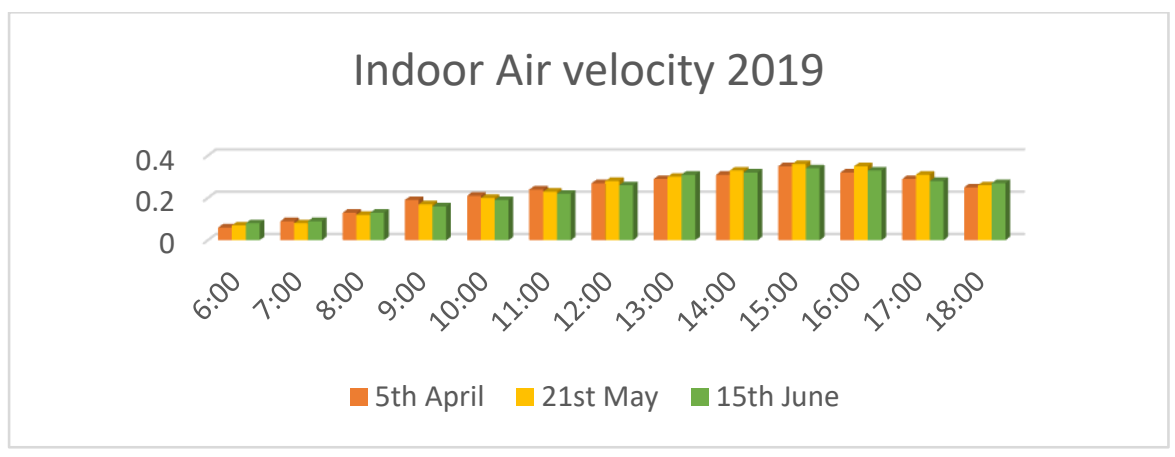

Figure 6 shows the total average air velocity and air flow rate for the year 2019 
The lowest and the highest values of indoor air velocities recorded are $0.06 \mathrm{~m} / \mathrm{s}$ and 0.35 $\mathrm{m} / \mathrm{s}, 0.07 \mathrm{~m} / \mathrm{s}$ and $0.36 \mathrm{~m} / \mathrm{s}, 0.08 \mathrm{~m} / \mathrm{s}$ and $0.34 \mathrm{~m} / \mathrm{s}$ while their averages are $0.21 \mathrm{~m} / \mathrm{s}, 0.22$ $\mathrm{m} / \mathrm{s}$ and $0.21 \mathrm{~m} / \mathrm{s}$ for April $5^{\text {th }}, 21^{\text {st }}$ May and $15^{\text {th }}$ June respectively.

\section{DISCUSSION}

A comparison of the recorded values of both indoor air temperature and velocity was carried out in order to ascertain the effect of the elements of natural ventilation incorporated in the renovation exercise conducted and the difference of $0.06 \mathrm{~m} / \mathrm{s}$ increases indoor air velocity was recorded. A reduction of $1^{\circ} \mathrm{C}$ indoor temperature was also recorded. This means that there is reduction in the indoor temperature while there is an increase in the indoor air velocity. In line with the ASHRAE standards, these differences will improve the thermal comfort of occupants.

\section{CONCLUSION}

In conclusion, this paper proves that there is an increase of $0.06 \mathrm{~m} / \mathrm{s}$ for indoor air velocity and $1.0^{\circ} \mathrm{C}$ in the effect of natural ventilation elements incorporated in the renovation exercise on the interior of the building as against same building before renovation exercise took place. According to increase in indoor air velocity and temperature will greatly enhance natural ventilation thereby aiding thermal comfort.

The specifications of mandatory temperatures or temperature ranges for rooms and buildings are regulated by many legislative directives such as ASHRAE standards. Generally, temperatures should always be evaluated in relation to the outside temperature. A difference of 5-6 K (temperature differences are specified in Kelvin, with $1 \mathrm{~K}$ equalling $1^{\circ} \mathrm{C}$ ) compared to the outside temperature has proven to be a viable definition whereby room temperatures of more than $26^{\circ} \mathrm{C}$ should be avoided. Designers are also encouraged to look into natural ventilation when carrying out renovation exercises.

\section{REFERENCES}

Abdulhamid, F \& Tukur, R. B 2019, 'enhancement of natural ventilation using solar chimney in hospital buildings', ATBU Journal Of Environmental Technology, vol 12, no 1, pp 101

Abdulhamid, F, Tukur, R.B \& Batagarawa A 2018, 'towards enhancing natural ventilation using integrated solar chimneys in hospital buildings', AARCHES National Conference, Zaria, pp 478.

Abdulhamid, F 2018, 'exploring solar chimneys to enhance natural ventilation towards aiding thermal comfort in the design of a proposed general hospital, Katsina', unpublished m.sc thesis, Department Of Architecture, Ahmadu Bello University, Zaria.

Abdullahi, MU 2015, 'application of energy efficiency strategies in the design of national library, Katsina', unpublished m.sc thesis, Department of Architecture, Ahmadu Bello University Zaria.

Atkinson J, Chartier Y, Pessoa-Silva CL, et al., editors. 2009, 'concepts and types of ventilation. Natural ventilation for infection control in health-care settings', World Health Organization, Geneva

Batia, A 2017, HVAC - natural ventilation principles, Continuing Education And Development, Inc, Course No: M04-038 lecture note.

Health and Safety Executives 2014, 'a publication on health and safety executives', Viewed 18 November 2016. www.hse.gov/temperature/thermal. 
Nazanin, N., Jones, P., \& Knight, I. 2008, 'workplace satisfaction and thermal comfort in air conditioned office buildings: findings from a summer survey and field survey in iran', Indoor Built Environment.

Nicol, J., Hunphreys, A., \& Roaf, S. 2012, 'adaptive thermal comfort: principles and practice', Oxon, UK Routlege.

Public H.N 2020,'types of healthcare systems in Nigeria', Viewed on 01 July 2021 https:/ / www.publichealth.com.ng/types-of-health-care-system-in-nigeria/

Tukur, R. B. 2013,' harnessing daylight potentials as a tool for thermal comfort in residential buildings, Unpublished PhD Thesis University of Nottingham.

Tolulope, D M \& Parastoo P. 2020, 'Bioclimatic Approach for Climate Classification of Nigeria', Licensee MDPI, Basel, Switzerland. 